\title{
Titrimetric and Spectrophotometric Assay of Oxcarbazepine in Pharmaceuticals Using N-Bromosuccinimide and Bromopyrogallol Red
}

\author{
Nagaraju Rajendraprasad, Kanakapura Basavaiah, and Kanakapura B. Vinay \\ Department of Chemistry, University of Mysore, Manasagangothri, Mysore-570 006, Karnataka, India \\ Correspondence should be addressed to Kanakapura Basavaiah, basavaiahk@yahoo.co.in \\ Received 13 January 2011; Accepted 4 May 2011 \\ Academic Editor: Mohamed Abdel-Rehim
}

Copyright ( 2011 Nagaraju Rajendraprasad et al. This is an open access article distributed under the Creative Commons Attribution License, which permits unrestricted use, distribution, and reproduction in any medium, provided the original work is properly cited.

Titrimetric and spectrophotometric methods are described for the determination of oxcarbazepine (OXC) in bulk drug and in tablets. The methods use N-bromosuccinimide (NBS) and bromopyrogallol red (BPR) as reagents. In titrimetry (method A), an acidified solution of OXC is titrated directly with NBS using methyl orange as indicator. Spectrophotometry (method B) involves the addition of known excess of NBS to an acidified solution of OXC followed by the determination of the unreacted NBS by reacting with BPR and measuring the absorbance of the unreacted dye at $460 \mathrm{~nm}$. Titrimetry allows the determination of $6-18 \mathrm{mg}$ of OXC and follows a reaction stoichiometry of $1: 1$ (OXC: NBS), whereas spectrophotometry is applicable over the concentration range of $0.8-8.0 \mu \mathrm{g} \mathrm{mL}^{-1}$. Method B with a calculated molar absorptivity of $2.52 \times 10^{4} \mathrm{~L} \mathrm{~mol}^{-1} \mathrm{~cm}^{-1}$ is the most sensitive spectrophotometric method ever developed for OXC. The optical characteristics such as limits of detection (LOD), quantification (LOQ), and Sandell's sensitivity values are also reported for the spectrophotometric method. The accuracy and precision of the methods were studied on intraday and interday basis. The methods described could usefully be applied to routine quality control of tablets containing OXC. No interference was observed from common pharmaceutical adjuvants. Statistical comparison of the results with a reference method shows an excellent agreement and indicates no significant difference in accuracy and precision. The reliability of the methods was further ascertained by recovery studies in standard addition procedure.

\section{Introduction}

Oxcarbazepine (OXC), (chemically known as 10,11-dihydro10 -oxo-5H-dibenzo[b,f]azepine-5-carboxamide), is a novel antiepileptic drug, which was developed as a second generation and a follow-up compound to carbamazepine. Clinically, it has been used to treat several types of epilepsy [1-3] and bipolar disorders [4].

The ever-increasing use of OXC in pharmaceutical formulations has necessitated its determination as a matter of foremost importance. OXC is not official in any Pharmacopoeia. Various analytical methods such as HPLC [58], HPTLC [9], GC [8], microemulsion electrokinetic chromatography [10], capillary electrokinetic chromatography $[11]$, voltammetry $[12,13]$ and capillary electrophoresis [14] have been reported for the determination of OXC in pharmaceuticals. However, these methods involve the use of expensive instruments which are not available at most quality control laboratories in developing and underdeveloped nations.

Titrimetry is still widely used in analytical chemistry for its superior speed and simplicity with little sacrifice in accuracy and precision. OXC is present in relatively large amounts ( 150 to $600 \mathrm{mg}$ per tablet) in pharmaceutical formulations. The simplicity and rapidity of titrimetry is more advantageous especially for macroanalysis over any instrumental methods. Since there is no stringent conditions to be maintained, more precise and accurate results are obtained from titrimetry. Because of one or the other advantage of titrimetry, it is widely applicable for the assay of many pharmaceutical compounds in many Pharmacopoeias. On the other hand, the spectrophotometric technique continues 
to be used in the assay of different classes of drugs in pure and in pharmaceutical formulations [15-18].

Despite being one of the most widely used antiepileptic drugs, no titrimetric method has been reported for OXC, and even a few visible spectrophotometric methods reported [19-21] suffer from one or another disadvantage. Of the two methods reported by Gandhimathi and Ravi [19], the first method uses Folin-Ciocalteu's (F-C) reagent in alkaline medium in which blue chromogen measured at $760 \mathrm{~nm}$, whereas the second method involves addition of a fixed volume of 3-methyl-2-benzothiazolinone hydrazine hydrochloride (MBTH) after treating of OXC with ferric chloride followed by the measurement of absorbance at $456 \mathrm{~nm}$. The methods obey Beer's law over the linear range of 5-30 and $10-50 \mu \mathrm{g} \mathrm{mL}^{-1}$ for F-C and MBTH methods, respectively, and the corresponding molar absorptivity values are $8.06 \times 10^{3}$ and $3.126 \times 10^{3} \mathrm{~L} \mathrm{~mol}^{-1} \mathrm{~cm}^{-1}$. In another report [20], OXC has been determined using iron(III) chloride and potassium hexacyanoferrate(III). The method is based on the reduction of iron(III) ions to iron(II) ions by drug, which in presence of hexacyanoferrate(III) produces green coloured chromogen measurable at $770 \mathrm{~nm}$. This method is applicable over the concentration range of 4$28 \mu \mathrm{g} \mathrm{mL}^{-1}$ OXC with the molar absorptivity value of $4.63 \times$ $10^{3} \mathrm{~L} \mathrm{~mol}^{-1} \mathrm{~cm}^{-1}$. The yellow chromogen with an absorption maximum at $430 \mathrm{~nm}$ formed by the reaction of OXC with methanolic $\mathrm{KOH}$ in DMSO medium as the basis for the assay of OXC (linear range $1.0-7.0 \mu \mathrm{g} \mathrm{mL}^{-1}$; molar absorptivity $1.21 \times 10^{4} \mathrm{~L} \mathrm{~mol}^{-1} \mathrm{~cm}^{-1}$ ) has been reported by Sathish and Nagendrappa [21].

All the four reported spectrophotometric methods are less sensitive besides employing either organic solvent medium or heating step.

In the present paper, we report one direct titrimetric $(\operatorname{method} \mathrm{A})$ and one indirect spectrophotometric (method B) methods using NBS as brominating agent in sulphuric acid medium for the assay of OXC. In titrimetry, the acidic solution of OXC was titrated with NBS in sulphuric acid medium. In spectrophotometry, for the first time, bromopyrogallol red (BPR) has been used to determine the unreacted NBS after completion of the reaction between OXC and NBS in sulphuric acid medium. The proposed methods are simple, highly accurate, and can be readily applied to the determination of OXC in bulk drug and in tablets.

\section{Experiment}

2.1. Apparatus. A Systronics model 106 digital spectrophotometer with $1 \mathrm{~cm}$ path length matched quartz cells was used to record the absorbance values.

2.2. Reagents and Standards. All chemicals used were of analytical reagent grade. Distilled water was used throughout the investigation.

Acetic acid $(2: 3$ and $1: 9 \mathrm{v} / \mathrm{v})$ and sulphuric acid $(10 \mathrm{M})$ were prepared by diluting appropriate volumes of their concentrated acids (99\% glacial acetic acid and 98\% sulphuric acid -both from Merck, Mumbai, India) with water. Two brands of tablets namely, Trioptal-300 (Novartis India Ltd, Mumbai, India) and Oxetol-600 (Sun Pharmaceuticals, Sikkim) were purchased from local commercial sources.

2.2.1. $\mathrm{N}$-Bromosuccinimide $\left(0.01 \mathrm{M}\right.$ and $\left.120 \mu \mathrm{g} \mathrm{mL}^{-1}\right)$. An approximately $0.01 \mathrm{M}$ solution was prepared by dissolving an accurately weighed quantity of NBS (Loba Chemie Ltd, Mumbai, India, assay 99) in water with the aid of heat. The solution was cooled to room temperature, standardized iodometrically, kept in an ambered coloured bottle, and stored at $4{ }^{\circ} \mathrm{C}$. For method B, NBS solution after standardization was diluted with water to get a working concentration of $120 \mu \mathrm{g} \mathrm{mL}^{-1}$.

2.2.2. Bromopyarogallol Red (BPR) (0.03\%). An aqueous $0.03 \%$ BPR solution was prepared daily afresh by dissolving an accurately weighed $30 \mathrm{mg}$ of the dye (Loba Chemie, Mumbai, India, purity $99 \%$ ) in $10 \mathrm{~mL}$ of methanol in a $100 \mathrm{~mL}$ volumetric flask, and the volume was made upto the mark with water.

2.2.3. Standard OXC Solution. A stock standard solution containing $2 \mathrm{mg} \mathrm{mL}^{-1}$ OXC was prepared by dissolving $200 \mathrm{mg}$ of pure OXC (Jubilant Organosys Ltd, Nanjangud, Mysore, India, purity $99.5 \%$ ) in $40 \mathrm{~mL}$ of glacial acetic acid; the volume was brought to $100 \mathrm{~mL}$ with water in a volumetric flask and used for assay in method A.

A $100 \mu \mathrm{g} \mathrm{mL}^{-1}$ OXC standard solution was also prepared by dissolving an accurately weighed $10 \mathrm{mg}$ of pure OXC in $10 \mathrm{~mL}$ of glacial acetic acid and diluting to the mark with water in a $100 \mathrm{~mL}$ calibrated flask, and this was diluted with $1: 9$ acetic acid to get a working concentration of $20 \mu \mathrm{g} \mathrm{mL}^{-1}$ OXC and used in method B.

\subsection{General Analytical Procedure}

2.3.1. Titrimetry (Method A). A 3-9 mL aliquot of pure drug solution containing 6-18 mg of OXC was accurately measured and transferred into a $100 \mathrm{~mL}$ titration flask. The total volume was brought to $10 \mathrm{~mL}$ by adding $2: 3$ acetic acid. Ten $\mathrm{mL}$ of $10 \mathrm{M} \mathrm{H}_{2} \mathrm{SO}_{4}$ was added, and the solution titrated with $0.01 \mathrm{M}$ NBS using a drop of methyl orange as indicator until the red colour disappeared. A blank titration was run and the necessary volume corrections were made. The amount of OXC in the measured aliquot was calculated from:

$$
\text { Amount }(\mathrm{mg})=V M_{w} \frac{R}{n},
$$

where $V=$ volume of NBS consumed, $\mathrm{mL}, M_{w}=$ relative molecular mass of drug (252.268), $R=$ molar concentration of NBS, and $n$ is the reaction stoichiometry (number of moles NBS reacting with each mole of OXC).

2.3.2. Spectrophotometry (Method B). Different aliquots $(0.4-4.0 \mathrm{~mL})$ of standard $20 \mu \mathrm{g} \mathrm{mL}^{-1}$ OXC solution were 
transferred into a series of $10 \mathrm{~mL}$ volumetric flasks using a microburette, and the total volume in all the flasks was adjusted to $4 \mathrm{~mL}$ by adding $1: 9$ acetic acid. To each flask, $1 \mathrm{~mL}$ each of $10 \mathrm{M} \mathrm{H}_{2} \mathrm{SO}_{4}$ and $120 \mu \mathrm{g} \mathrm{mL}^{-1}$ NBS solutions were added, the content was mixed well and kept aside for 30 min at room temperature with occasional shaking. Finally, $1 \mathrm{~mL}$ of $0.03 \%$ BPR was added to each flask and the volume was made up to mark with water. Then, the absorbance of the unreacted dye was measured at $460 \mathrm{~nm}$ against reagent blank prepared similarly without OXC.

A standard graph was prepared by plotting absorbance against concentration, and the unknown concentration was read from the standard graph or computed from the regression equation derived using Beer's law data.

\subsection{Procedure for the Analysis of Tablets}

2.4.1. Method A. Twenty tablets were weighed and finely powdered. An accurately weighed quantity of the tablet powder equivalent to $200 \mathrm{mg}$ OXC was transferred into a $100 \mathrm{~mL}$ volumetric flask, and about $40 \mathrm{~mL}$ of glacial acetic acid was added. The content of the flask was shaken for $10 \mathrm{~min}, 30 \mathrm{~mL}$ of water was added, shaken for 10 more min, and finally the volume was completed to the mark with water. The content was mixed well and filtered through a Whatman no. 42 filter paper. First $10 \mathrm{~mL}$ portion of the filtrate was discarded and a suitable aliquot (say $5 \mathrm{~mL}$ ) was then subjected to analysis by following the procedure described earlier.

2.4.2. Method B. A quantity of tablet powder containing $10 \mathrm{mg}$ of OXC was transferred into a $100 \mathrm{~mL}$ volumetric flask containing $10 \mathrm{~mL}$ of glacial acetic acid. The content was shaken for $5 \mathrm{~min}, 50 \mathrm{~mL}$ of water was added, and content was mixed well and shaken again for 15 more min. The mixture was diluted to the mark with water and filtered using Whatman no. 42 filter paper. First $10 \mathrm{~mL}$ portion of the filtrate was discarded and the resulting tablet extract $\left(100 \mu \mathrm{g} \mathrm{mL}^{-1}\right.$ in OXC) was diluted to $20 \mu \mathrm{g} \mathrm{mL}^{-1}$ with $1: 9$ acetic acid. Suitable aliquot was then subjected to analysis by following the general procedure.

\subsection{Procedures for the Analysis of Placebo Blank and Synthetic} Mixture. A placebo blank containing starch $(10 \mathrm{mg})$, acacia (15 mg), hydroxyl cellulose (10 mg), sodium citrate (10 mg), talc $(20 \mathrm{mg})$, magnesium stearate $(15 \mathrm{mg})$ and sodium alginate $(10 \mathrm{mg})$ was prepared by combining all components to form a homogeneous mixture. A $5 \mathrm{mg}$ of the placebo blank was accurately weighed and its solution was prepared as described under "tablets", and then subjected to analysis by following the general procedure.

A synthetic mixture was prepared by adding an accurately weighed $200 \mathrm{mg}$ of OXC to the placebo mentioned above. The extraction procedure for tablets as described for method A and method B were applied separately by taking required quantity of synthetic mixture to prepare $2 \mathrm{mg} \mathrm{mL}^{-1}$ and $20 \mu \mathrm{g} \mathrm{mL}^{-1}$ OXC solutions, respectively. Three different volumes of the resulting synthetic mixture solution (Equivalent

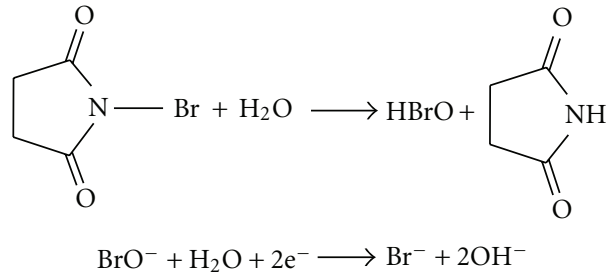

Scheme 1: Hydrolysis of NBS to produce hypobromous acid/ monovalent bromine.

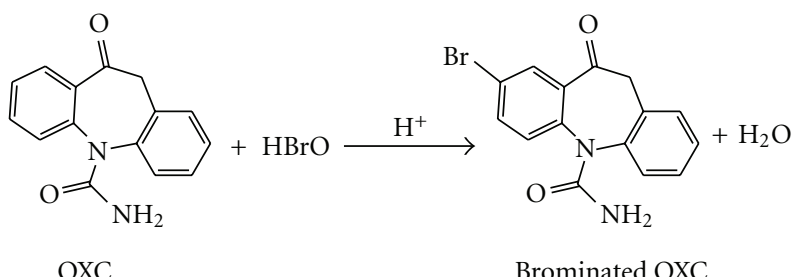

Scheme 2: Suggested reaction pathway for the bromination of OXC.

to 6,12 and $18 \mathrm{mg}$ OXC in method $\mathrm{A} ; 2,4$ and $6 \mu \mathrm{gmL} \mathrm{mL}^{-1}$ in method B) were subjected to analysis by following the respective general procedure.

\section{Chemistry}

$\mathrm{N}$-Bromosuccinimide contains unstably bound bromine and is used for bromination in organic chemistry [22]. In the reactions where NBS used as brominating agent, the monovalent positive bromine of the NBS (the bond between bromine and nitrogen is polarized by the two neighbouring carbonyl groups) is responsible for bromination. The formation of the monovalent bromine due to hydrolysis of NBS is as shown in Scheme 1.

The proposed methods are based on the bromination of the drug by NBS in sulphuric acid medium. The suggested reaction pathway for the bromination of OXC is given in Scheme 2.

In the proposed titrimetric method, OXC is directly titrated with NBS in sulphuric acid medium. The reaction between OXC and NBS was found to occur in $1: 1$ (drug:NBS) stoichiometric ratio, and all the calculations are based on this fact. Using $0.01 \mathrm{M}$ NBS, $6-18 \mathrm{mg}$ of OXC was conveniently determined. In spectrophotometry, a known excess of NBS was treated with OXC and after the reaction between OXC and NBS ensured to be complete, the unreacted NBS was reacted with a fixed concentration of BPR followed by the measurement of residual dye at $460 \mathrm{~nm}$ (Figure 1 and Scheme 3).

\section{Results and Discussions}

\subsection{Method Development: Optimization of Experimental Variables}

4.1.1. Method A. A series of experiments was performed to select the solvent system to dissolve OXC. The drug is not 


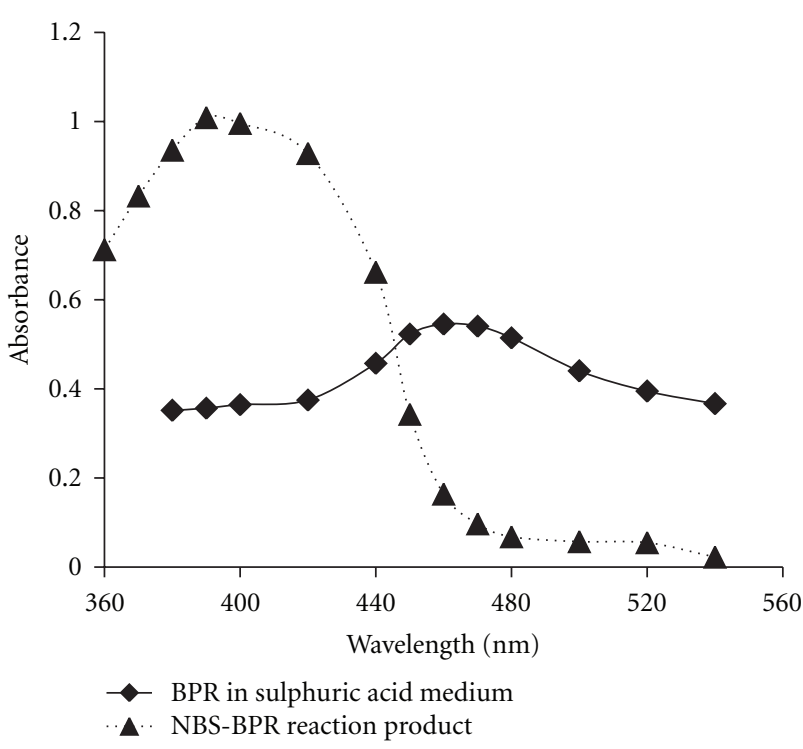

FIGURE 1: Absorption spectra of BPR in sulphuric acid medium and the reagent blank (bromoderivative of the dye, BPR).

soluble in any of the solvents like water, $\mathrm{HCl}, \mathrm{H}_{2} \mathrm{SO}_{4}, \mathrm{HNO}_{3}$, and $\mathrm{H}_{3} \mathrm{PO}_{4}$ except acetic and perchloric acids. The titration was not feasible in perchloric acid medium. The titration was performed in the presence of different volumes and different concentrations of perchloric acid. No consistent stoichiometry was obtained at any volume/concentration of perchloric acid. At very high concentrations of perchloric acid, blank consumption was more, and at lower concentrations no reaction of OXC with NBS took place. The drug solution was found to be unstable when stored for longer time, and colloidal particles were observed when OXC was dissolved in acetic acid of concentration lower than $2: 3$ (acetic acid: water). Therefore, 2:3 acetic acid was used as solvent system.

Preliminary experiments were carried out to choose the proper medium for the quantitative and stoichiometric reaction between OXC and NBS. Sulphuric acid medium yielded a consistent stoichiometry with sharp end point. The reaction was rapid and quantitative when $8-12 \mathrm{~mL}$ of $10 \mathrm{M} \mathrm{H}_{2} \mathrm{SO}_{4}$ in a total volume of $20 \mathrm{~mL}$ was maintained. When the volume was less than $8 \mathrm{~mL}$ and greater than $12 \mathrm{~mL}$, slightly lower and higher stoichiometric ratios, respectively, were observed. Therefore, $10 \mathrm{~mL}$ of $10 \mathrm{M} \mathrm{H}_{2} \mathrm{SO}_{4}$ was used throughout the investigation. Under the optimized reaction conditions, a definite reaction stoichiometry of $1: 1$ (OXC: NBS) was found for the range of 6-18 mg of OXC.

\subsubsection{Method B}

(1) Absorption Spectra. BPR in $\mathrm{H}_{2} \mathrm{SO}_{4}$ medium is red in colour and exhibited an absorption maximum at $460 \mathrm{~nm}$. Addition of BPR to NBS resulted in the formation of yellow coloured product (bromo derivative of BPR) with an absorption maximum at $390 \mathrm{~nm}$. OXC and NBS had no absorption at either 460 or $390 \mathrm{~nm}$. When increasing concentrations of OXC were reacted with a fixed concentration of NBS in acid medium, there occurred a concomitant decrease in the concentration of NBS. Addition of a fixed concentration of BPR to decreasing concentrations of NBS resulted in a proportional increase in the concentration of residual BPR leading to a linear increase in absorbance at $460 \mathrm{~nm}$ with the drug concentration, which formed the basis for the assay. Figure 1 illustrates the absorption spectra of BPR, and the reaction product formed between NBS and BPR in the absence of OXC (reagent blank).

(2) Selection of Reaction Medium. OXC solution in dilute acetic acid (1:9) is stable for longer time (more than two days) at $4{ }^{\circ} \mathrm{C}$. The reaction between OXC and NBS was performed in different acid media. Better results were obtained in sulphuric acid medium. The effect of acid concentration on the reaction between OXC and NBS was studied by varying the concentration of $\mathrm{H}_{2} \mathrm{SO}_{4}$ keeping the concentrations of NBS and drug fixed. The reaction was found to be rapid yielding a constant absorbance with maximum sensitivity and stability when the $\mathrm{H}_{2} \mathrm{SO}_{4}$ concentration was maintained in the range of $0.7-1.3 \mathrm{M}$ $(0.7$ to $1.3 \mathrm{~mL}$ of $10 \mathrm{M}$ in a total volume of $10 \mathrm{~mL})$. The same acid concentration was found sufficient for the instantaneous reaction between unreacted NBS and BPR. At acid concentrations higher than $1.5 \mathrm{M}$, the solution becomes cloudy. Therefore, $1 \mathrm{~mL}$ of $10 \mathrm{M} \mathrm{H}_{2} \mathrm{SO}_{4}$ in a total volume of $10 \mathrm{~mL}$ was used throughout the work.

(3) Optimization of NBS. To fix the optimum concentration of NBS, different concentrations of NBS were reacted with a fixed concentration of $\mathrm{BPR}$ in $\mathrm{H}_{2} \mathrm{SO}_{4}$ medium and the absorbance was measured at $460 \mathrm{~nm}$. A constant and minimum absorbance resulted with $12 \mu \mathrm{g} \mathrm{mL}^{-1} \mathrm{NBS}$ and, hence, different concentrations of OXC were reacted with $1 \mathrm{~mL}$ of $120 \mu \mathrm{g} \mathrm{mL}^{-1} \mathrm{NBS}$ in $\mathrm{H}_{2} \mathrm{SO}_{4}$ medium before determining the residual NBS via the reaction Scheme illustrated earlier. This facilitated the optimization of the linear dynamic range over which procedure could be applied for the assay of OXC.

(4) Optimization of BPR. To fix the upper Beer's law limit with respect to $\mathrm{BPR}$, different concentrations of the dye were reacted with a fixed $1 \mathrm{~mL}$ of $120 \mu \mathrm{g} \mathrm{mL}^{-1} \mathrm{NBS}$ in sulphuric acid medium. After the reaction between NBS and BPR was ensured to be complete, the absorbance of the unreacted BPR was measured at $460 \mathrm{~nm}$. It was found that a reproducible and minimum absorbance value was obtained when $1 \mathrm{~mL}$ of $0.03 \%$ BPR used. Hence, $1 \mathrm{~mL}$ of $0.03 \%$ of BPR was used throughout the investigation.

(5) Study of Reaction Time and Stability of the Coloured Species. Under the described experimental conditions, the reaction between OXC and NBS was complete within $30 \mathrm{~min}$ (Figure 2$)$ at room temperature $\left(28 \pm 2{ }^{\circ} \mathrm{C}\right)$. After the addition of BPR, the reaction between NBS and dye was instantaneous and the absorbance of the unreacted dye was stable for at least $45 \mathrm{~min}$, thereafter. 

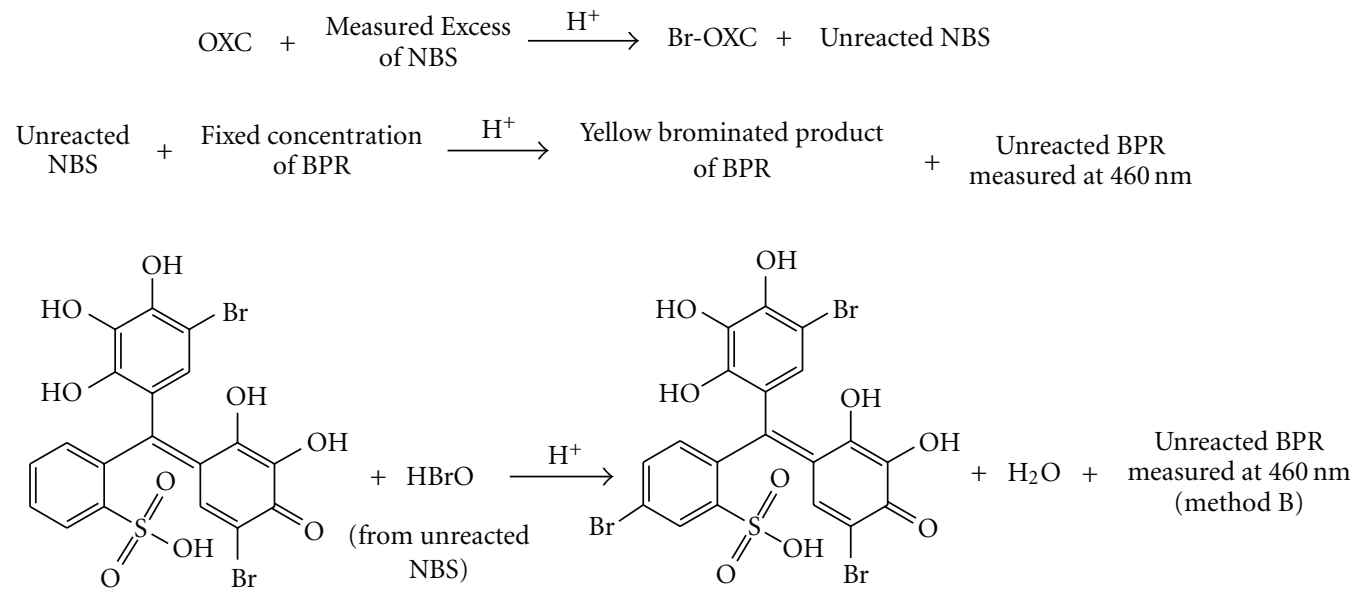

BPR

Yellow brominated product

with absorption maximum

at $390 \mathrm{~nm}$

Scheme 3: Tentative reaction pathway for the formation of yellow coloured bromo-derivative of BPR (method B).

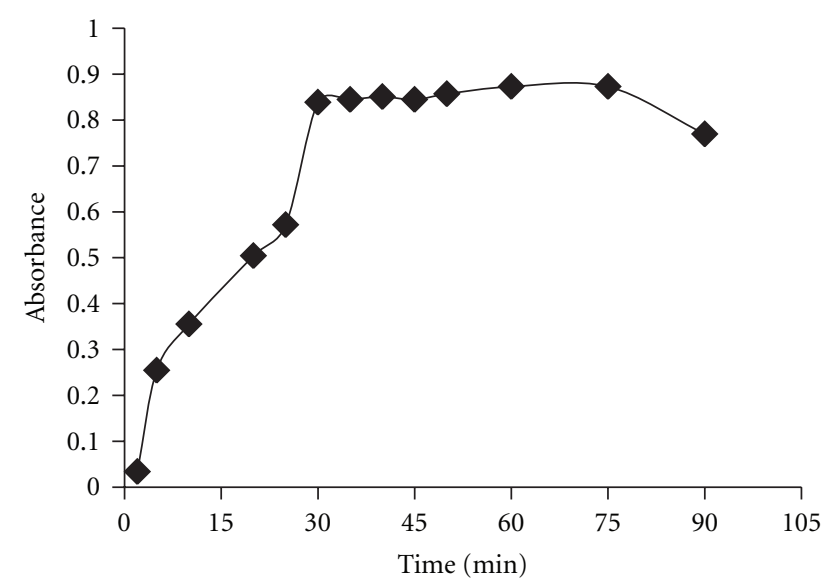

FIGURE 2: Study of reaction time between NBS and OXC in sulphuric acid medium and stability of the coloured species by measuring the absorbance of the unreacted BPR after reacting with NBS.

(6) Effect of Diluent. In order to select proper solvent for dilution, solvents like 1:9 acetic acid, water, methanol and $10 \mathrm{M} \mathrm{H}_{2} \mathrm{SO}_{4}$ were tried. Satisfactory results were obtained when water was used as the diluent.

\subsection{Method Validation}

4.2.1. Linearity and Sensitivity. Over the range investigated (6-18 mg), a fixed reaction stoichiometry of $1: 1$ [OXC:NBS] was obtained in titrimetry which served as the basis for calculations. The relationship between the drug amount and the volume of titrant consumed was examined. The linearity between two parameters is apparent from the correlation coefficient of 0.9955 obtained by the method of least squares. From this, it is implied that the reaction between OXC and NBS proceeds stoichiometrically in the ratio $1: 1$ in the range studied. In spectrophotometry, the calibration graph was found to be linear from 0.8 to $8.0 \mu \mathrm{g} \mathrm{mL}^{-1}$ OXC. The measured absorbance values were plotted versus concentration. The least square calibration equation was $A=0.1044 \mathrm{C}-0.0113$ [where the concentration (C) is measured in $\mu \mathrm{g} \mathrm{mL} \mathrm{mL}^{-1}$ ] with a regression coefficient of $0.9993(n=5)$. The calculated molar absorptivity and Sandell sensitivity values are $2.52 \times 10^{4} \mathrm{~L} \mathrm{~mol}^{-1} \mathrm{~cm}^{-1}$ and $0.010 \mu \mathrm{g} \mathrm{cm}^{-2}$, respectively. The limits of detection (LOD) and quantification (LOQ) were calculated according to the ICH guidelines [23] using the formulae:

LOD $=3.3 \mathrm{~S} /$ slope and LOQ $=10 \mathrm{~S} /$ slope, (where $S$ is the standard deviation of the absorbance of six blank readings). The calculated LOD and LOQ are 0.28 and $0.86 \mu \mathrm{g} \mathrm{mL}^{-1}$, respectively.

4.2.2. Accuracy and Precision. The repeatability of the proposed methods was determined by performing replicate determinations $(n=7)$. The intraday and interday variation in the analysis of OXC was measured at three different levels. The accuracy of an analytical method expresses the closeness between the reference value and the found value. Accuracy was evaluated as percentage relative error between the measured and taken amounts/concentrations. The results of this study are compiled in Table 1 and speak of good intermediate precision $(\% \mathrm{RSD} \leq 3.06)$ and accuracy (\%RE $\leq 3.75)$ of the results.

4.2.3. Selectivity. In the analysis of placebo blank, the volume of NBS consumed was the same as that of the indicator blank (method A) and in spectrophotometry, the absorbance of the placebo blank was not different from that of the reagent blank suggesting the noninterference by the inactive ingredients added to prepare the placebo. 
TABLE 1: Intraday and interday accuracy and precision.

\begin{tabular}{lccccccc}
\hline \multirow{2}{*}{ Method* } & \multirow{2}{*}{ OXC taken } & \multicolumn{2}{c}{ Intra-day accuracy and precision } & \multicolumn{3}{c}{ Inter-day accuracy and precision } \\
& & OXC found & RE\% & RSD\% & OXC found & RE\% & RSD\% \\
\hline \multirow{2}{*}{ A } & 6.0 & 6.17 & 2.83 & 2.22 & 6.18 & 3.12 & 2.98 \\
& 12.0 & 12.28 & 2.33 & 1.98 & 11.73 & 2.22 & 3.06 \\
& 18.0 & 17.73 & 1.50 & 1.53 & 18.34 & 1.89 & 2.23 \\
\hline \multirow{3}{*}{ B } & 2.0 & 1.95 & 2.50 & 2.30 & 2.04 & 2.12 & 1.99 \\
& 4.0 & 4.07 & 1.75 & 1.20 & 3.94 & 1.52 & 1.58 \\
& 6.0 & 5.92 & 1.33 & 2.70 & 6.13 & 2.20 & 1.60 \\
\hline
\end{tabular}

* In method A, OXC taken/found are in $\mathrm{mg}$ and they are $\mu \mathrm{g} \mathrm{mL}{ }^{-1}$ in method B.

TABLe 2: Results obtained for the study of effect of matrix by the analysis of synthetic mixture.

\begin{tabular}{lccc}
\hline Method* $^{*}$ & $\begin{array}{c}\text { OXC in synthetic } \\
\text { mixture }\end{array}$ & OXC found $^{*}$ & \%Recovery \pm SD \\
\hline \multirow{2}{*}{ A } & 6.0 & 5.92 & $98.66 \pm 0.62$ \\
& 12.0 & 12.07 & $100.6 \pm 1.22$ \\
& 18.0 & 18.56 & $103.1 \pm 1.74$ \\
\hline \multirow{3}{*}{ B } & 2.0 & 2.03 & $101.4 \pm 1.56$ \\
& 4.0 & 3.96 & $99.11 \pm 0.85$ \\
& 6.0 & 6.29 & $104.9 \pm 1.14$ \\
\hline
\end{tabular}

${ }^{*}$ In method A, OXC taken/found are in $\mathrm{mg}$ and they are $\mu \mathrm{g} \mathrm{mL}^{-1}$ in method B.

\#Mean value of three determinations.

In method $\mathrm{A}$, three different aliquots of the synthetic mixture extract were analyzed titrimetrically $(n=3$ in each case), which yielded a \% recovery values in the range from 98.66 to 103.1 of OXC with standard deviation values in the range of $0.62-1.74$. In spectrophotometry, three different aliquots of $20 \mu \mathrm{g} \mathrm{mL}^{-1}$ OXC were subjected to analysis $(n=$ $3)$. The recovery values of $99.11-104.9 \%$ OXC with standard deviation $0.85-1.56$ were obtained. These results which are close to $100 \%$ recovery complement the findings of the placebo blank analysis with respect to selectivity. The detailed results are presented in Table 2.

4.2.4. Robustness and Ruggedness. To evaluate the robustness of the methods, volume of $\mathrm{H}_{2} \mathrm{SO}_{4}$ was slightly altered (10 $\pm 1 \mathrm{~mL}$ ) with reference to optimum values in titrimetry. However, in spectrophotometry, the reaction time (after adding NBS, time varied was $30 \pm 2 \mathrm{~min}$ ) and volume of BPR $(1 \pm 0.2 \mathrm{~mL}$ of $0.03 \%)$ were slightly altered. To check the ruggedness, analysis was performed by four different analysts, and on three different burettes (method A) or spectrophotometers (method B) by the same analyst. The robustness and the ruggedness were checked at three different drug levels $(6,12$, and $18 \mathrm{mg}$ in method A; 2, 4, and $6 \mu \mathrm{g} \mathrm{mL}^{-1}$ in method $\left.\mathrm{B}\right)$. The intermediate precision, expressed as percent RSD, which is a measure of robustness and ruggedness, was within the acceptable limits (1.26$3.15 \%)$ as shown in Table 3.

4.2.5. Application to Tablet Analysis. Commercial OXC tablets were analyzed using the developed methods and also by a reference published method [19]. The method is based on spectrophotometric determination of OXC using $\mathrm{F}-\mathrm{C}$ reagent in alkaline medium. The results obtained were compared statistically by the Student's $t$-test and the variance-ratio $F$-test [24]. The calculated $t$ - and $F$-values did not exceed the tabulated values of $2.77(t)$ and 6.39 $(F)$ at the $95 \%$ confidence level and for four degrees of freedom, indicating close similarity between the proposed methods and the reference method with respect to accuracy and precision. These results are summarized in Table 4.

4.2.6. Recovery Study. To further ascertain the accuracy and reliability of the methods, recovery experiments were performed via standard-addition procedure. Preanalyzed tablet powder was spiked $\left(6 \mathrm{mg}\right.$ in method $\mathrm{A} ; 2 \mu \mathrm{g} \mathrm{mL}^{-1}$ in method B) with pure OXC at three different levels $(3,6$, and $9 \mathrm{mg}$ in method A; 1,2 , and $3 \mu \mathrm{g} \mathrm{mL}^{-1}$ in method B), and the total was found by the proposed methods. Each determination was repeated three times. The percent recovery of pure OXC added (Table 5) was within the permissible limits indicating the absence of interference by the inactive ingredients in the assay.

\section{Conclusions}

One titrimetric and one new spectrophotometric method were developed and validated for the determination of oxcarbazepine using NBS as brominating agent. The titrimetric method, first to be reported for oxcarbazepine, is applicable over a semi-micro-scale (6-18 mg), and using spectrophotometry at a small concentration as $0.86 \mu \mathrm{g} \mathrm{mL}^{-1}$ drug can be determined with confidence and with a fair degree of accuracy and precision. The new approach of utilizing NBS and bromopyrogallol red as reagents in spectrophotometry is the first of such reports. The method is the most sensitive ever developed for oxcarbazepine, though somewhat less rapid requiring a standing time of $30 \mathrm{~min}$. Both methods are simple, accurate, and precise and are free from extreme experimental conditions such as heating at high temperature and use of organic solvent unlike in some reported methods. Both the methods were applied successfully to the determination of OXC in tablets. Compared to many existing instrumental methods for oxcarbazepine, the proposed spectrophotometric method has two additional advantages of simplicity of operations and low-cost instrument. Both 
TABLE 3: Robustness and ruggedness.

\begin{tabular}{|c|c|c|c|c|c|c|c|c|}
\hline \multicolumn{5}{|c|}{ Method A } & \multicolumn{4}{|c|}{ Method B } \\
\hline \multirow{3}{*}{$\begin{array}{l}\text { OXC } \\
\text { studied } \\
\text { mg }\end{array}$} & \multirow{3}{*}{$\begin{array}{c}\text { Robustness } \\
\text { (RSD, \%) } \\
\text { Volume of } \mathrm{H}_{2} \mathrm{SO}_{4} \\
\quad(n=3)\end{array}$} & \multicolumn{2}{|c|}{ Ruggedness (RSD, \%) } & \multirow{3}{*}{$\begin{array}{l}\text { OXC } \\
\text { studied } \\
\mu \mathrm{g} \mathrm{mL}^{-1}\end{array}$} & \multirow{2}{*}{\multicolumn{2}{|c|}{$\begin{array}{l}\text { Robustness (RSD, \%) } \\
\text { Conditions altered* }\end{array}$}} & \multicolumn{2}{|c|}{ Ruggedness (RSD, \%) } \\
\hline & & & & & & & Inter-analysts & Inter-instruments \\
\hline & & $\begin{array}{c}\text { Inter-analysis } \\
\quad(n=4)\end{array}$ & $\begin{array}{c}\text { Inter-burettes } \\
\quad(n=4)\end{array}$ & & $\begin{array}{l}\text { Volume of BPR } \\
\qquad(n=3)\end{array}$ & $\begin{array}{l}\text { Reaction time } \\
\quad(n=3)\end{array}$ & $(n=4)$ & $(n=3)$ \\
\hline 6.0 & 3.10 & 2.22 & 2.89 & 2.0 & 3.15 & 1.52 & 2.21 & 1.89 \\
\hline 12.0 & 2.69 & 1.89 & 2.65 & 4.0 & 3.02 & 2.56 & 1.89 & 1.56 \\
\hline 18.0 & 2.50 & 1.56 & 2.56 & 6.0 & 2.10 & 1.26 & 2.00 & 2.13 \\
\hline
\end{tabular}

${ }^{*}$ In method $\mathrm{A}$, volumes of $10 \mathrm{M} \mathrm{H}_{2} \mathrm{SO}_{4}$ varied were $10 \pm 1 \mathrm{~mL}$, In method $\mathrm{B}$, volumes of BPR varied were $1 \pm 0.1 \mathrm{~mL}$, and the reaction time employed was 30 \pm 2 min.

TABLE 4: Results of analysis of tablets by the proposed methods.

\begin{tabular}{|c|c|c|c|c|}
\hline \multirow{2}{*}{ Tablets analysed } & \multirow{2}{*}{ Label claim, mg/tablet } & \multicolumn{3}{|c|}{ Found* (Percent of label claim \pm SD) } \\
\hline & & Reference method & Method A & Method B \\
\hline \multirow{3}{*}{ Trioptal 300} & & & $97.33 \pm 0.89$ & $98.66 \pm 1.12$ \\
\hline & 300 & $98.14 \pm 1.56$ & $t=1.04$ & $t=0.61$ \\
\hline & & & $F=3.07$ & $F=1.94$ \\
\hline \multirow{3}{*}{ Oxetol 600} & & & $101.3 \pm 1.56$ & $100.2 \pm 0.93$ \\
\hline & 600 & $102.1 \pm 1.26$ & $t=\mathbf{0 . 8 9}$ & $t=2.74$ \\
\hline & & & $F=1.53$ & $F=1.84$ \\
\hline
\end{tabular}

* Mean value of five determinations.

TABLE 5: Accuracy assessment by recovery experiments.

\begin{tabular}{|c|c|c|c|c|c|c|c|c|}
\hline \multirow{2}{*}{$\begin{array}{l}\text { Tablets } \\
\text { studied }\end{array}$} & \multicolumn{4}{|c|}{ Method A } & \multicolumn{4}{|c|}{ Method B } \\
\hline & $\begin{array}{l}\text { OXC in } \\
\text { tablet, mg }\end{array}$ & $\begin{array}{l}\text { Pure OXC } \\
\text { added,mg }\end{array}$ & $\begin{array}{l}\text { Total } \\
\text { found, mg }\end{array}$ & $\begin{array}{l}\text { Pure OXC } \\
\text { recovered*, } \\
\text { Percent } \pm \text { SD }\end{array}$ & $\begin{array}{l}\text { OXC in } \\
\text { tablet, } \\
\mu \mathrm{g} \mathrm{mL}^{-1}\end{array}$ & $\begin{array}{l}\text { Pure OXC } \\
\text { added, } \\
\mu \mathrm{g} \mathrm{mL}^{-1}\end{array}$ & $\begin{array}{l}\text { Total } \\
\text { found, } \\
\mu \mathrm{g} \mathrm{mL}^{-1}\end{array}$ & $\begin{array}{l}\text { Pure OXC } \\
\text { recovered } \\
\text { Percent } \pm \\
\text { SD }\end{array}$ \\
\hline \multirow{3}{*}{ Oxetol 600} & 6.08 & 3.0 & 9.01 & $97.67 \pm 0.56$ & 2.00 & 1.00 & 3.02 & $101.6 \pm 1.12$ \\
\hline & 6.08 & 6.0 & 12.43 & $105.83 \pm 1.78$ & 2.00 & 2.00 & 4.01 & $100.6 \pm 0.88$ \\
\hline & 6.08 & 9.0 & 14.78 & $96.67 \pm 0.58$ & 2.00 & 3.00 & 5.14 & $104.5 \pm 1.45$ \\
\hline
\end{tabular}

${ }^{*}$ Mean value of three determinations.

the methods make use of very easily available and cheaper reagents which demonstrates their cost-effectiveness. These advantageous features advocate their use in quality control laboratories for routine use.

\section{Acknowledgments}

The authors thank Jubilant Organosys Ltd., Nanjangud, Mysore, India, for gifting pure oxcarbazepine. Two of the authors (N. Rajendraprasad and K. B. Vinay) thank the authorities of the University of Mysore, Mysore, for permission and facilities. One of the authors (N.R.P) thanks the University Grants Commission, New Delhi, India, for awarding Meritorious Research Scholarship.

\section{References}

[1] S. M. Grant and D. Faulds, "Oxcarbazepine: a review of its pharmacology and therapeutic potential in epilepsy, trigeminal neuralgia and affective disorders," Drugs, vol. 43, no. 6, pp. 873-888, 1992.

[2] A. D. Fraser, "New drugs for the treatment of epilepsy," Clinical Biochemistry, vol. 29, no. 2, pp. 97-110, 1996.

[3] M. M. Kalis and N. A. Huff, "Oxcarbazepine, an antiepileptic agent," Clinical Therapeutics, vol. 23, no. 5, pp. 680-700, 2001.

[4] A. Musenga, M. A. Saracino, G. Sani, and M. A. Raggi, "Antipsychotic and antiepileptic drugs in bipolar disorder: the importance of therapeutic drug monitoring," Current Medicinal Chemistry, vol. 16, no. 12, pp. 1463-1481, 2009.

[5] J. M. Juenke, P. I. Brown, F. M. Urry, and G. A. McMillin, "Drug monitoring and toxicology: a procedure for the monitoring of oxcarbazepine metabolite by HPLC-UV," Journal of Chromatographic Science, vol. 44, no. 1, pp. 45-48, 2006.

[6] M. L. Qi, P. Wang, L. J. Wang, and R. N. Fu, "LC method for the determination of oxcarbazepine in pharmaceutical preparations," Journal of Pharmaceutical and Biomedical Analysis, vol. 31, no. 1, pp. 57-62, 2003.

[7] K. S. Rao, N. Belorkar, and M. E. B. Rao, "Development and validation of stability-indicating liquid chromatographic 
method for the quantitative determination of oxcarbazepine in tablet dosage forms," Journal of Young Pharmacists, vol. 1, no. 3, pp. 270-277, 2009.

[8] E. Greiner-Sosanko, S. Giannoutsos, D. R. Lower, M. A. Virji, and M. D. Krasowski, "Drug monitoring: simultaneous analysis of lamotrigine, oxcarbazepine, 10-hydroxycarbazepine, and zonisamide by HPLC-UV and a rapid GC method using a nitrogen-phosphorus detector for levetiracetam," Journal of Chromatographic Science, vol. 45, no. 9, pp. 616-622, 2007.

[9] T. S. Reddy and P. S. Devi, "Validation of a high-performance thin-layer chromatographic method with densitometric detection for quantitative analysis of two anticonvulsants in tablets," Journal of Planar Chromatography-Modern TLC, vol. 20, no. 6, pp. 451-456, 2007.

[10] M. Ivanova, E. Marziali, M. A. Raggi, and E. Kenndler, "Microemulsion electrokinetic chromatography for the separation of carbamazepine, oxcarbazepine, and their metabolites," Journal of Separation Science, vol. 25, no. 14, pp. 863$871,2002$.

[11] E. Marziali, M. A. Raggi, N. Komarova, and E. Kenndler, "Octakis-6-sulfato- $\gamma$-cyclodextrin as additive for capillary electrokinetic chromatography of dibenzoazepines: carbamazepine, oxcarbamazepine and their metabolites," Electrophoresis, vol. 23, no. 17, pp. 3020-3026, 2002.

[12] M. E. B. Calvo, O. D. Renedo, and M. J. A. Martínez, "Determination of oxcarbazepine by square wave adsorptive stripping voltammetry in pharmaceutical preparations," Journal of Pharmaceutical and Biomedical Analysis, vol. 43, no. 3, pp. 1156-1160, 2007.

[13] O. Domínguez-Renedo, M. E. B. Calvo, M. A. Alonso-Lomillo, and M. J. Arcos-Martínez, "Oxcarbazepine analysis by adsorptive stripping voltammetry using silver nanoparticle-modified carbon screen-printed electrodes," Sensor Letters, vol. 8, no. 2, pp. 268-272, 2010.

[14] B. Paw and K. Woś, "Development and validation of a capillary electrophoresis method for determination of oxcarbazepine and zonisamide in pharmaceuticals," Journal of Pre-Clinical and Clinical Research, vol. 2, no. 2, pp. 157-159, 2008.

[15] B. G. Gowda, M. B. Melwanki, and J. Seetharamappa, "Spectrophotometric determination of certain vicinal dihydroxybenzene derivatives in pharmaceutical preparations," Analytical Sciences, vol. 17, no. 4, pp. 533-534, 2001.

[16] K. C. Ramesh, B. G. Gowda, M. B. Melwanki, J. Seetharamappa, and J. Keshavayya, "Extractive spectrophotometric determination of antiallergic drugs in pharmaceutical formulations using bromopyrogallol red and bromothymol blue," Analytical Sciences, vol. 17, no. 9, pp. 1101-1103, 2001.

[17] B. G. Gowda, M. B. Melwanki, and J. Seetharamappa, "Extractive spectrophotometric determination of ceterizine $\mathrm{HCl}$ in pharmaceutical preparations," Journal of Pharmaceutical and Biomedical Analysis, vol. 25, no. 5-6, pp. 1021-1026, 2001.

[18] B. S. Nagaralli, J. Seetharamappa, and M. B. Melwanki, "Sensitive spectrophotometric methods for the determination of amoxycillin, ciprofloxacin and piroxicam in pure and pharmaceutical formulations," Journal of Pharmaceutical and Biomedical Analysis, vol. 29, no. 5, pp. 859-864, 2002.

[19] M. Gandhimathi and T. K. Ravi, "Use of Folin-Ciocalteu phenol reagent and 3-methyl-2-benzothiazolinone hydrazine hydrochloride in the determination of oxcarbazepine in pharmaceuticals," Acta Pharmaceutica, vol. 58, no. 1, pp. 111118,2008
[20] C. S. Ramaa, P. P. Chothe, A. A. Naik, and V. J. Kadam, "Spectrophotometric method for the estimation of oxcarbazepine in tablets," Indian Journal of Pharmaceutical Sciences, vol. 68, no. 2, pp. 265-266, 2006.

[21] M. A. Sathish and G. Nagendrappa, "Spectrophotometric determination of oxcarbazepine in pharmaceutical formulations," International Journal of Pharmacy and Pharmaceutical Sciences, vol. 2, no. 3, pp. 93-98, 2010.

[22] M. Hudlicky, Preparatvni Reakce v Organicke Chemii II, Halogenace a Dehalogenace, NCSAV, Prague, Czech Republic, 1955.

[23] "ICH harmonised tripartite guideline, validation of analytical procedures: text and methodology Q2(R 1)," in Proceedings of the International Conference on Hormonisation of Technical Requirements for Registration of Pharmaceuticals for Human Use, London, UK, November 2005.

[24] J. Inczedy, T. Lengyel, and A. M. Ure, IUPAC Compendium of Analytical Nomenclature: Definitive Rules, Blackwell Science, Boston, Mass, USA, 1998. 


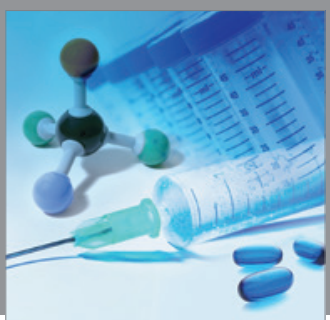

International Journal of

Medicinal Chemistry

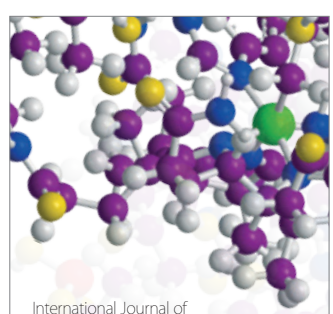

Carbohydrate Chemistry

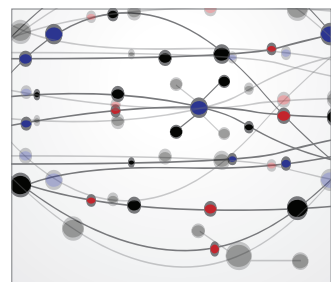

The Scientific World Journal
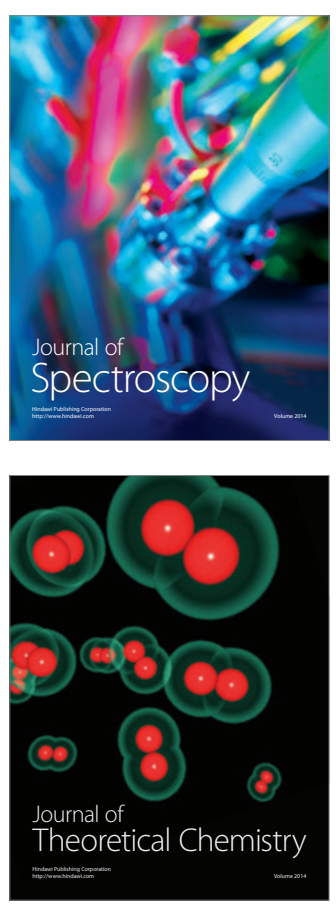
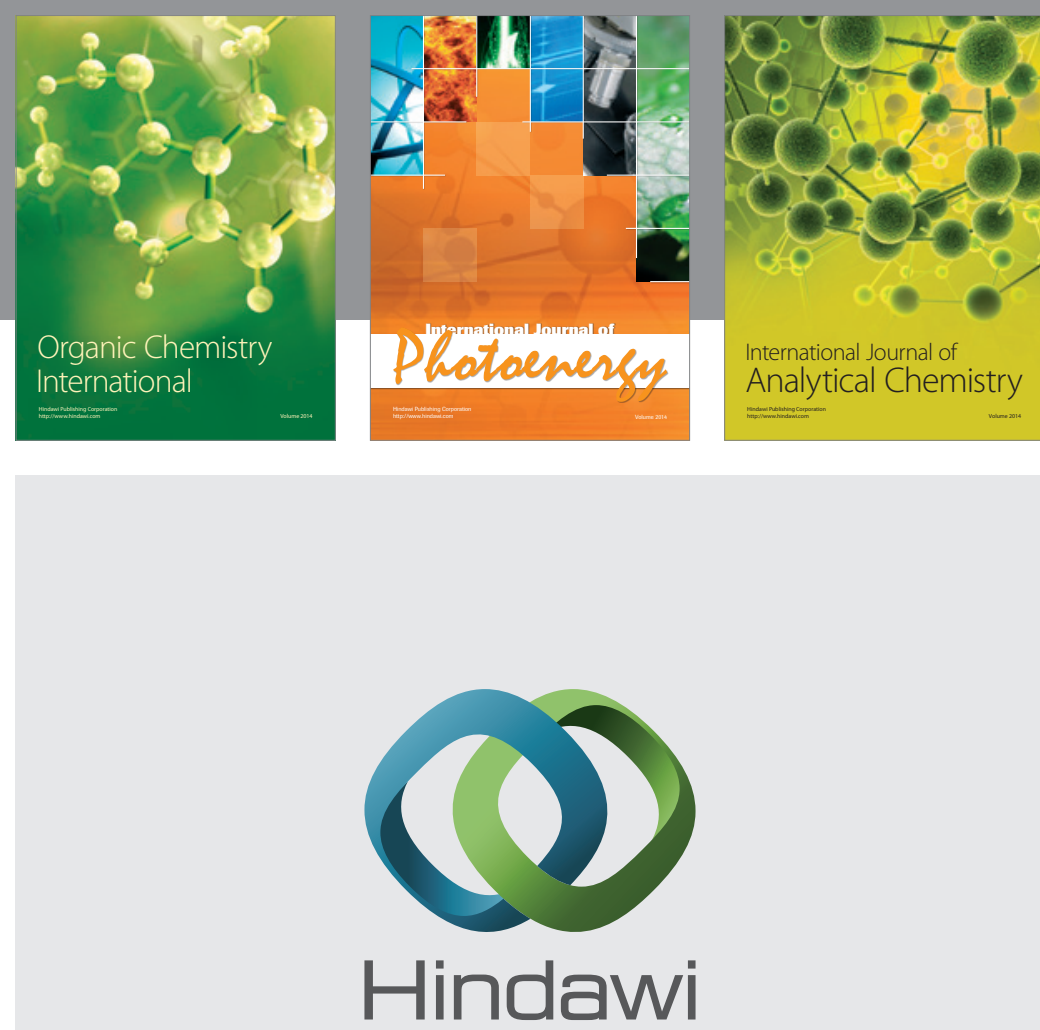

Submit your manuscripts at

http://www.hindawi.com
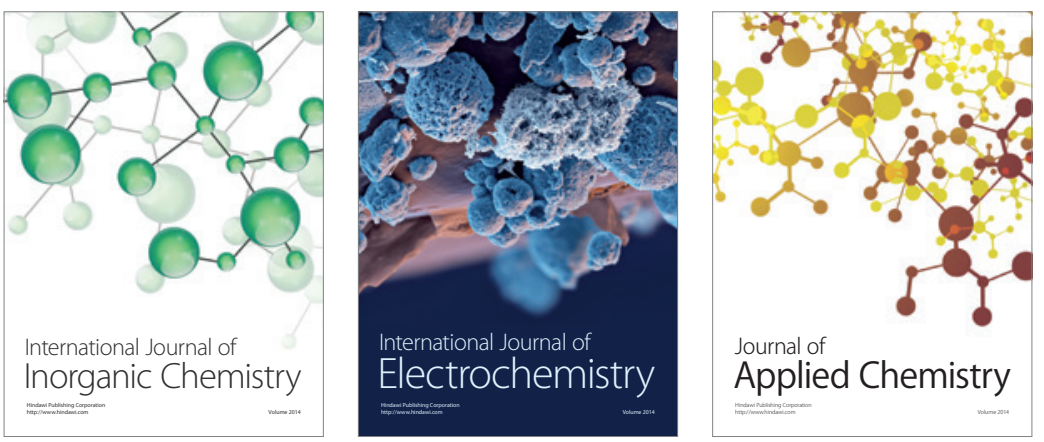

Journal of

Applied Chemistry
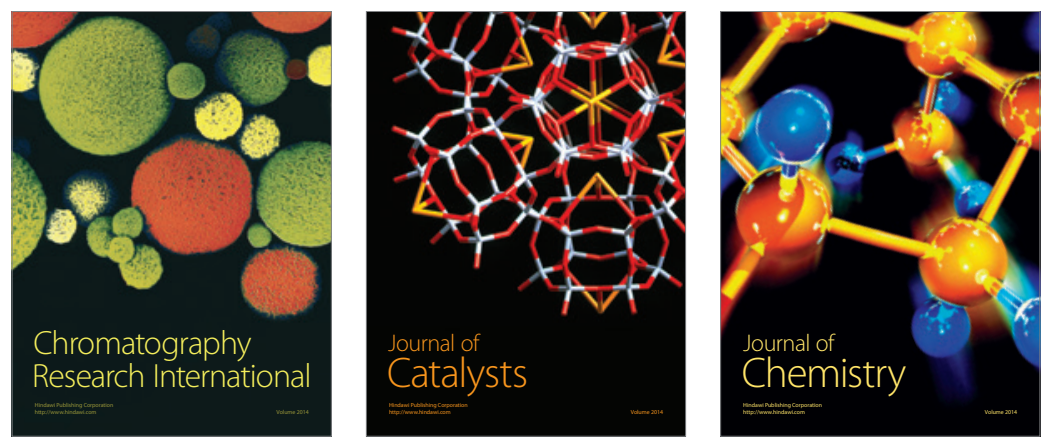
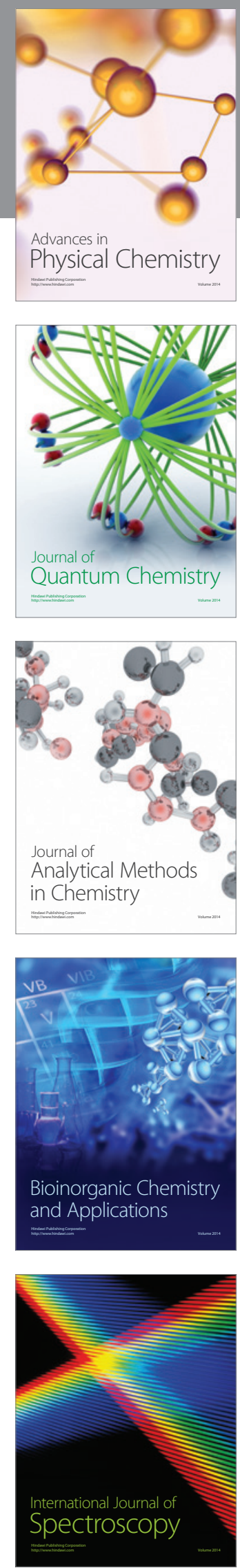